\title{
Effect of Different Cover Cultivations in Later Summer on Aroma Constituents of Autumn Tea (Camellia sinensis L.)
}

\author{
Min Liu ${ }^{*}$, Fucan $\mathrm{Xie}^{1 *}$, Renrong Cao ${ }^{2}$, Xiaohua Qi1 ${ }^{1}$ Xuehao Chen ${ }^{1 \#}$ \\ ${ }^{1}$ School of Horticulture and Plant Protection, Yangzhou University, Yangzhou, China \\ ${ }^{2}$ Tea Research Institute of Jiangsu Province, Jurong, China \\ Email: ${ }^{*}$ hhchen@yzu.edu.cn
}

Received 12 August 2014

\begin{abstract}
Tea plants grown under sunshade net and greenhouse are new methods for coping with hightemperature stress in later summer in middle and south China. Aroma is one of the most important flavors and qualities of tea. In this research the cultivar "Longjing-changye" (LJCY) was grown under sunshade net, greenhouse and open field as treatments to study the changes of aromatic substances by using Head Space Solid Phase-microextraction and Gas Chromatography-Mass Spectrometry (HS-SPME/GC-MS). The results showed that tea plants grown under sunshade net and greenhouse had higher content of aroma substances in autumn tea. Those growing conditions are good for improving the contents of the ester and geraniol with floral and fruity fragrance in autumn tea. Moreover, overshadowing in summer is helpful to improve fragrance of fresh tea leaves quality in autumn tea, particularly the $50 \%$ sunshade net.
\end{abstract}

\section{Keywords}

Cultivation Conditions, HS-SPME, GC-MS, Aroma, Tea

\section{Introduction}

The characteristic fragrance of tea, the "aroma" of either infused leaf or the tea liquor, is one of the most important factors for evaluation of its quality [1] [2]. The source of the tea aroma is attributed to various volatile organic compounds (VOCs) present in tea. These VOCs are formed as a result of significant lipid degradations during the tea processing periods. For example, the majority of the aroma compounds are formed from amino acids, fatty acids, carotenoids and glycosides [3].

At present, the production of traditional and better green tea only harvested in spring. Spring is very short for the growth of tea plants, which results in a lack of fresh raw tea leaves, so it is difficult to meet the market need of tea. It is not difficult to see that it needs to break the limitations of raw materials of spring green tea and in-

\footnotetext{
"These authors contributed equally to this work.

\#Corresponding author.
}

How to cite this paper: Liu, M., Xie, F.C., Cao, R.R., Qi, X.H. and Chen, X.H. (2014) Effect of Different Cover Cultivations in Later Summer on Aroma Constituents of Autumn Tea (Camellia sinensis L.). Journal of Agricultural Chemistry and Environment, 3, 1-6. http://dx.doi.org/10.4236/jacen.2014.34B001 
crease the output of fresh tea in other seasons by changing cultivation conditions for tea plants. In recent years, some new cultivation techniques in tea have developed to improve the quality of tea.

In order to improve the quality of autumn tea, we may let tea plants grow under sunshade net or greenhouse in summer which will improve the micro-climate for tea plants in later summer. Such a condition can yield a harmonious ecological environment and regulate the relationship between "metabolic source" and "metabolic pool". Although the previous studies showed that it is good for improving the quality and production of tea with properly covering the sunshade net during summer, the impact on the aroma of tea fresh leaves has not been reported yet [4]. In this research, we will compare the changes in aroma contents of LJCY tea grown in greenhouse, sunshade net and open field conditions, respectively. The results will be helpful to explore the influence on the quality of aroma in fresh tea leaves harvested in autumn with a variety of cultivation. It also can provide technical base to optimize tea cultivation conditions.

\section{Materials and Methods}

\subsection{Materials}

Tea plants ("Longjingchangye” LJCY; Camellia sinensis) were grown under 50\% and $75 \%$ shading net and greenhouse (from June 1, 2011 to September 10, 2011). Fresh young tea buds were harvested from the same cultivar of tea plants grown under greenhouse, sunshade net and open field of Tea Research Institute of Jiangsu province in China in October 2011 and kept at $-80^{\circ} \mathrm{C}$ till determination of aroma extraction.

\subsection{Measurement of Micro-Climate in Different Conditions}

We set up 5 sampling points in each condition from the tea cultivar "LJCY”. By making use of the temperature and humidity measuring instruments and light intensity meter, the data related to the environmental factors were measured and recorded during the sunshade net treatment (from June 1, 2011 to September 10, 2011) on 8:00, 13:00 and 17:00 of each day. Averages of 5 duplication are calculated and used for statistical analysis.

\subsection{Extraction and Concentration of Volatile Components}

For each sample $2.00 \mathrm{~g}$ of tea, previously homogenised, were weighed into a $10 \mathrm{ml}$ vial, and infused with $3 \mathrm{ml}$ boiling water, the vial was sealed with tetrafluoroethylene and immediately kept at $80^{\circ} \mathrm{C}$ to equilibrate for 5 min in a water bath; then, the extraction was performed with a $75 \mu \mathrm{m}$ Carboxen/PDMS extraction head. After sampling during $30 \mathrm{~min}$, the SPME fibre was introduced into the GC injector, and left for $3.5 \mathrm{~min}$ to allow the analytes thermal desorption [5] [6].

\subsection{Gas Chromatography-Mass Spectrometry (GC-MS) Analysis}

The analysis of volatile compounds obtained by SPME and SDE was performed by means of a GC-MS using an Agilent 5975C mass selective detector coupled to an Agilent 7890AGC (Agilent, Santa Clara, CA), equipped with HP-5MS capillary column $(30 \times 0.25 \mathrm{~mm}$ inner diameter, $0.25 \mu \mathrm{m}$ film thickness). Helium was used as carrier gas, and the flow rate was $1 \mathrm{~mL} \cdot \mathrm{min}^{-1}$. For the $\mathrm{SDE}, 0.1 \mu \mathrm{L}$ concentration was injected in splitless mode at $250^{\circ} \mathrm{C}$; for SPME analysis, desorption was also in splitless mode at $250^{\circ} \mathrm{C}$ for $5 \mathrm{~min}$. The GC oven temperature gradient was: $50^{\circ} \mathrm{C}$ (held for $2 \mathrm{~min}$ ) initially, and finally increased to $260^{\circ} \mathrm{C}$ (held for $5 \mathrm{~min}$ ) at $5^{\circ} \mathrm{C} \cdot \mathrm{min}^{-1}$. The transfer line temperature was $280^{\circ} \mathrm{C}$. Electron impact (EI) spectra were recorded at $70 \mathrm{eV}$, the ion source temperature was $250^{\circ} \mathrm{C}$, and the mass spectra were scanned in an $\mathrm{m} / \mathrm{z}$ range of 40 to 500 mass units. Compounds were tentatively identified by using the NIST147, NIST27 and WILEY7 mass spectra library. Each compound was further confirmed by comparing its mass spectra, linear retention index (LRI), and retention times with those obtained for the standards [7] [8].

\section{Results}

\subsection{Difference of the Environment Conditions under the Different Facilities}

As shown in Table 1, the actual transmittance of $75 \%$ and 50\% sunshade net treatments $74.65 \%$ and $50.13 \%$, respectively, and $65.44 \%$ for greenhouse cover, that is to say, the actual shading degree was $34.56 \%$. Compared 
with the open field, the temperature of greenhouse was $1.40^{\circ} \mathrm{C}$ higher. However, that of $75 \%$ and $50 \%$ shading net were 2.40 and 2.60 lower, respectively (Table 2). The relative humidity of greenhouse, $75 \%$ and $50 \%$ shading net increased by $4.80 \%, 7.6 \%$ and $2.8 \%$, respectively (Table 2 ).

\subsection{Sunshade Net and Greenhouse Treatment Alters the Composition of Aroma Components}

An aroma extract obtained by HS-SPME extraction of the representative LJCY tea sample was subjected to GC-MS analysis. Ninety aroma-active compounds were perceived by panel-lists (Table 3), including 8 lactones, 4 alcohols, 5 allyl compounds other 2 compounds. It was obvious that were the major group in LJCY tea. Lactone compounds accounted for $43.16 \%$ of the total aroma constituents of LJCY grown in the open field compared to the ester compounds and contents of lactone compounds of LJCY grown under greenhouse and 50\% shading net increased by $14.99 \%$ and $23.49 \%$, respectively. However that decreased by $7.62 \%$ under $75 \%$ shading net.

Contents of alcohol components of LJCY grown under the different conditions but the open field were increased. They increased by $10.22 \%$ in greenhouse condition, and $6.62 \%, 9.94 \%$ for $50 \%$ and $75 \%$ shading net conditions, respectively. Likewise, the contents of allyl compounds of LJCY grown under different facilities were higher than that in the open field (Table 3). However, the contents of 3-methylene-1,1-2-methyl vinyl

Table 1. Comparison of illumination intensity and light penetrability under the conditions of greenhouse, sunshade net and open field. The light penetrability is the ratio of the light intensity in facilities conditions and that in the open field.

\begin{tabular}{|c|c|c|c|c|c|c|c|c|c|}
\hline & \multirow[b]{2}{*}{ Time } & \multicolumn{4}{|c|}{ Illumination intensity $\left(\times 10^{2}\right.$ Lux $)$} & \multicolumn{4}{|c|}{ Light penetrability (\%) } \\
\hline & & Open field & $\begin{array}{l}75 \% \text { sun- } \\
\text { shade net }\end{array}$ & $\begin{array}{l}50 \% \text { sun- } \\
\text { shade net }\end{array}$ & Greenhouse & Open field & $\begin{array}{l}75 \% \text { sun- } \\
\text { shade net }\end{array}$ & $\begin{array}{l}50 \% \text { sun- } \\
\text { shade net }\end{array}$ & Greenhouse \\
\hline \multirow{4}{*}{ Fine days } & 8:00 & 545.9 & 137.1 & 273.2 & 313.4 & 0.0 & 25.1 & 50.0 & 57.4 \\
\hline & 13:00 & 813.2 & 218.6 & 408.7 & 556.1 & 0.0 & 26.9 & 50.3 & 68.4 \\
\hline & 17:00 & 156.6 & 40.7 & 77.8 & 104.4 & 0.0 & 26.0 & 49.7 & 66.7 \\
\hline & Mean & 505.2 & 132.1 & 253.2 & 324.6 & 0.0 & 26.0 & 50.0 & 64.2 \\
\hline \multirow{4}{*}{ Fine days } & 8:00 & 248.9 & 64.1 & 123.9 & 184.0 & 0.0 & 25.8 & 49.8 & 73.9 \\
\hline & 13:00 & 343.0 & 78.9 & 150.5 & 209.4 & 0.0 & 23.0 & 49.7 & 61.0 \\
\hline & $17: 00$ & 46.3 & 11.7 & 22.7 & 29.3 & 0.0 & 25.3 & 49.7 & 63.3 \\
\hline & Mean & 212.7 & 51.6 & 99.0 & 140.9 & 0.0 & 24.7 & 49.7 & 66.1 \\
\hline
\end{tabular}

Table 2. Comparison of temperature and relative humidity under the conditions of greenhouse and sunshade net and open field.

\begin{tabular}{|c|c|c|c|c|c|c|c|c|c|}
\hline & \multirow{2}{*}{ Time } & \multicolumn{4}{|c|}{ Temperature $\left({ }^{\circ} \mathrm{C}\right)$} & \multicolumn{4}{|c|}{ Relative humidity (\%) } \\
\hline & & Open field & $\begin{array}{l}75 \% \text { sun- } \\
\text { shade net }\end{array}$ & $\begin{array}{l}50 \% \text { sun- } \\
\text { shade net }\end{array}$ & Greenhouse & Open field & $\begin{array}{l}75 \% \text { sun- } \\
\text { shade net }\end{array}$ & $\begin{array}{l}50 \% \text { sun- } \\
\text { shade net }\end{array}$ & Greenhouse \\
\hline \multirow{4}{*}{ Fine days } & $8: 00$ & 27.1 & 25.0 & 25.5 & 27.9 & 40.7 & 48.6 & 48.5 & 49.8 \\
\hline & 13:00 & 33.0 & 30.4 & 29.6 & 34.2 & 32.3 & 36.7 & 33.0 & 34.9 \\
\hline & $17: 00$ & 27.6 & 25.7 & 25.6 & 28.3 & 56.9 & 60.6 & 52.1 & 53.4 \\
\hline & Mean & 29.2 & 27.0 & 26.9 & 30.1 & 43.3 & 48.6 & 44.5 & 46.0 \\
\hline \multirow{4}{*}{ Fine days } & 8:00 & 25.7 & 22.0 & 23.1 & 25.7 & 54.0 & 69.2 & 59.8 & 64.8 \\
\hline & $13: 00$ & 27.5 & 24.0 & 24.4 & 27.0 & 42.8 & 54.1 & 49.6 & 52.5 \\
\hline & $17: 00$ & 23.5 & 22.0 & 21.9 & 23.5 & 64.7 & 68.2 & 65.4 & 65.3 \\
\hline & Mean & 25.6 & 22.7 & 23.1 & 25.4 & 53.8 & 63.8 & 58.3 & 60.9 \\
\hline
\end{tabular}


cyclohexane and 1-(2-aminoethyl) aziridine were decreased (Table 3).

As shown in Figure 1, among all kinds of cultivation conditions tested, LJCY grown under 75\% shading net

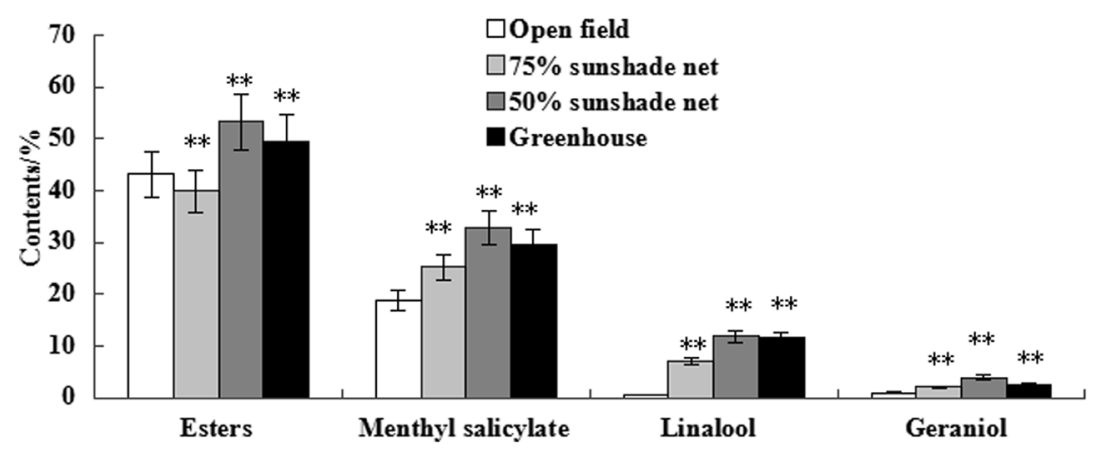

Figure 1. The esters, menthyl salicylate, linalool and geraniol accumulations in LJCY tea buds under greenhouse, sunshade net and open field conditions. Error bars indicate Standard deviation \pm SD of three biological replicates. The two asterisks show very significant differences at the $1 \%$ level.

Table 3. Variation in the volatile flavour compounds of LJCY tea grown under greenhouse, sunshade net and open field. The ratio is the specific value of the aromatic substances contents in LJCY tea grown under greenhouse or sunshade net and that in the open field. the sign "-" denotes an negative growth.

\begin{tabular}{|c|c|c|c|c|c|c|c|}
\hline Aromatic substances & Open field (CK) & Greenhouse & Ratio/\% & $\begin{array}{l}50 \% \text { sun- } \\
\text { shade net }\end{array}$ & Ratio/\% & $\begin{array}{l}75 \% \text { sun- } \\
\text { shade net }\end{array}$ & Ratio/\% \\
\hline Hexenyl acetate & 18.88 & 15.89 & -15.84 & 14.75 & -21.88 & 10.19 & -46.03 \\
\hline Cis-3-hexenyl caproate & 0.89 & 1.51 & 69.66 & 1.93 & 116.85 & 1.34 & 50.56 \\
\hline menthyl salicylate & 18.88 & 29.65 & 57.04 & 32.73 & 73.36 & 25.22 & 33.58 \\
\hline Cis-3-hexenyl valerate & 0.77 & 0.86 & 11.69 & 1.13 & 46.75 & 0.61 & -20.78 \\
\hline Toluene acid butyrate & 2.30 & 0.21 & -90.87 & 0.72 & -68.70 & 1.26 & -45.22 \\
\hline Anti-2-hexenoic acid butyl ester & 0.60 & 0.13 & -78.33 & 0.41 & -31.67 & 0.17 & -71.67 \\
\hline Anti-2-hexenyl hexanoate & 0.07 & 0.22 & 214.29 & 0.21 & 200.00 & 0.03 & -57.14 \\
\hline CIS-3-hexene butyric acid ester & 0.77 & 1.16 & 50.66 & 1.42 & 84.42 & 1.05 & 36.36 \\
\hline Total esters & 43.16 & 49.63 & 14.99 & 53.30 & 23.49 & 39.87 & -7.62 \\
\hline phytol & 0.81 & 0.70 & -13.58 & 1.27 & 56.79 & 1.81 & 123.46 \\
\hline linalool & 0.60 & 11.60 & 1833.33 & 11.92 & 1886.67 & 7.17 & 1095.00 \\
\hline Geraniol & 1.00 & 2.05 & 105.00 & 3.97 & 297.00 & 2.45 & 145.00 \\
\hline 3-hexenol & 13.01 & 11.29 & -13.22 & 4.88 & -62.49 & 13.93 & 7.07 \\
\hline Total alcohol & 15.42 & 25.64 & 66.28 & 22.04 & 42.93 & 25.36 & 64.46 \\
\hline Caryophyllene & 0.06 & 0.05 & -16.67 & 0.05 & -16.67 & 0.13 & 116.67 \\
\hline$\beta$-pinene & 0.77 & 1.33 & 72.73 & 0.97 & 25.97 & 3.05 & 296.10 \\
\hline laurene & 0.60 & 1.19 & 98.33 & 1.30 & 116.67 & 1.39 & 131.67 \\
\hline$\beta$-bourbonene & 0.72 & 1.29 & 79.17 & 1.19 & 65.28 & 0.58 & -19.44 \\
\hline$\alpha$-muurolene & 1.09 & 3.22 & 195.41 & 1.92 & 76.15 & 4.28 & 292.66 \\
\hline Total vinyl & 3.24 & 7.08 & 118.52 & 5.43 & 67.59 & 9.43 & 191.05 \\
\hline 1-(2-aminoethyl) aziridine & 14.41 & 7.46 & -48.23 & 8.67 & -39.83 & 13.73 & -4.71 \\
\hline $\begin{array}{l}\text { 3-methylene-1,1-2-methyl vinyl } \\
\text { cyclohexane }\end{array}$ & 18.88 & 1.50 & -92.02 & 1.02 & -94.60 & 2.43 & -87.13 \\
\hline
\end{tabular}


condition contained the lowest level of ester $(\mathrm{p}<0.01)$ while the highest $(\mathrm{p}<0.01)$ for tea plants grown under $50 \%$ shading net condition. The biggest increase of aroma components in LJCY tea grown under three conditions are methylis salicylas, followed by linalool and geraniol in ordercompared with the open field (Figure 1).

\section{Discussion}

The aromatic substances in tea is the general term for various kinds of volatile substances. The aroma indicates that the tea comprises at least one of certain numbers of odours that are desirable and are highly valued in "good quality tea”. Its composition is very complex, which included alcohol, aldehydes, acids, esters, ketones, terpenes and other aromatic substances in the fresh tea leaves [9] [10]. Besides the typical astringent and bitter taste, in particular, the characteristic aroma of the tea beverage is an important criterion in the evaluation of the tea quality. Also LJCY tea is one of the most popular tea beverages in China, appreciated by consumers mostly for its characteristic taste, color and flavor.

Optimum temperature for tea plants growth is between $20^{\circ} \mathrm{C}$ and $30^{\circ} \mathrm{C}$ and relative humidity of air is around $75 \%$. Based on our research, as shown in Table 2, shading treatments on tea can reduce the temperature of summer. Temperature of greenhouse is slightly higher than the open field is due to the poor ventilation of greenhouse. The sunshade net and greenhouse covers can improve air relative humidity. As shown in Table $\mathbf{1}$ and Table 2, the sunshade net cultivation is more suitable for the growth of tea plants in summer.

In alcohol components, the key aroma-active compounds were probably a-terpineol, b-linalool, linalool oxide III, linalool oxide IV and geraniol in terms of their aroma intensities, and these alcohols also provide fruity and floral notes. It has been previously reported that a-terpineol was one of the major components contributing to the odour of smoked Lapsang Souchong [11] and that geraniol was found to be one of the characteristic volatile components in Keemun black tea [12] as well as Kangra orthodox black tea [13]. Furthermore, phytol was also detected in green tea powder produced from shade-grown leaves and used as an indicator of shading treatment [14]. Our research showed that LJCY tea harvested in autumn and grown under shading conditions released out more fruity and floral fragrance (Table 3), which is the same as the previous study [14].

Generally speaking, the content of aromatic substances in spring tea buds are higher than than that in autumn tea, which is one reason that the spring tea smell much more aroma. In fact, most acids existed in esters form or were changed into aldehydes, alcohols, hydrocarbons, or other secondary metabolites [15]. This research also showed that the contents of terpene alcohols such as linalool and geraniol with flower and fruit aroma in fresh tea buds grown under sunshade net and greenhouse were higher than that in the open field (Figure 1). Tea plants grown under sunshade net and greenhouse were richer of aroma substances in autumn tea.

The aroma-active compounds detected above by our research were most likely the crucial and characteristic aromatic compounds determining the special flavour of LJCY tea. Previous studies showed that the low molecular chain of alcohols and esters are highly volatile with a very delicate odor, especially $C_{5}-C_{8}$ compounds [16]. Linalool is known for lily of the valley aroma and described as a complex woody and light scent, and reported as a major flavour component of orthodox Kangra tea [17]. In this study, the LJCY tea grown under shading conditions with higher lactones and inalool contents were found, which indicated that LJCY tea grown under shading facilities is highly delicate odor (Figure 1).

\section{Conclusion}

In conclusion, shading in summer is helpful to improve the aroma quality of fresh buds of autumn tea and more conducive to improve the contents of ester and geraniol aromatic substances with floral and fruit flavor of fresh autumn tea buds, especially the $50 \%$ sunshade net.

\section{Acknowledgements}

We thank the experimental tea farm of the Tea Research Institute of Jiangsu province for all treatments and sampling. This research was financially supported by Jiangsu Science and Technolgy project (BE2012326).

\section{References}

[1] Horie, H., Fukatsu, S., Mukai, T., Kawanaka, T.G.M., Shimohara, T. and Sens (1992) Quality Evaluation of Green Tea (Sencha) by Sensory Test and NIR Method. Chagyo Kenkyu Hokoku (Tea Research Journal), 76, 39-44. 
http://dx.doi.org/10.5979/cha.1992.76_39

[2] Togari, N., Kobayashi, A. and Aishim, T. (1995) Pattern Recognition Applied to Gas Chromatographic Profiles of Volatile Components in Three Tea Categories. Food Research International, 28, 495-502. http://dx.doi.org/10.1016/0963-9969(95)00029-1

[3] Yamanishi, T. (1981) In Tea, Coffee and Cocoa and Other Beverages. In: Teranishi, R., Flath, R.A. and Sigisawa, H. Eds., Flavour Research, Marcell Dekker, New York, 231-304.

[4] Li, W.J., Yang, P.X. and Li, X.P. (2003) Effects of Shading on the Tea Compounds of Tea New Shoots. China Tea. (In Chinese)

[5] Jumtee, K., Komura, H., Bamba, T. and Fukusaki, E. (2011) Predication of Japanese Green Tea (Sen-cha) Ranking by Volatile Profiling Using Gas Chromatography Mass Spectrometry and Multivariate Analysis. Journal of Bioscience and Bioengineering, 112, 252-255. http://dx.doi.org/10.1016/j.jbiosc.2011.05.008

[6] Vichi, S., Guadayol, J.M., Caixach, J., López-Tamames, E. and Buxaderas, S. (2007) Comparative Study of Differentextraction Techniques for the Analysis of Virginolive Oil Aroma. Food Chemistry, 105, 1171-1178. http://dx.doi.org/10.1016/j.foodchem.2007.02.018

[7] Du, L.P., Li, J.X., Li, W., Li, Y.F., Li, T. and Xiao, D.G. (2014) Characterization of Volatile Compounds of Pu-erh Tea Using Solid-Phasemicroextraction and Simultaneous Distillation-Extraction Coupled with Gas Chromatography-Mass Spectrometry. Food Research International, 57, 61-70. http://dx.doi.org/10.1016/j.foodres.2014.01.008

[8] Tat, L., Comuzzo, P., Stolfo, I. and Battistutta, F. (2005). Optimization of Wine Head-Space Analysis by Solid-Phase Microextraction Capillary Gas Chromatography with Mass Spectrometric and Flame Ionization Detection. Food Chemistry, 93, 361-369. http://dx.doi.org/10.1016/j.foodchem.2004.11.025

[9] Wang, L.F., Lee, J.Y., Chung, J.O., Baik, J.H., So, S. and Park, S.K. (2008) Discrimination of Teas with Different Degrees of Fermentation by SPME-GC Analysis of the Characteristic Volatile Flavour Compounds. Food Chemistry, 109, 196-206. http://dx.doi.org/10.1016/j.foodchem.2007.12.054

[10] Xu, X., Yan, M. and Zhu, Y. (2005) Influence of Fungal Fermentation on the Development of Volatile Compounds in the Puer Tea Manufacturing Process. Engineering in Life Sciences, 5, 382-386. http://dx.doi.org/10.1002/elsc.200520083

[11] Yao, S.S., Guo, W.F., Lu, Y. and Jiang, Y.X. (2005) Flavor Characteristics of Lapsang Souchong and Smoked Lapsang Souchong, a Special Chinese Black Tea with Pine Smoking Process. Journal of Agricultural and Food Chemistry, 53, 8688-8693. http://dx.doi.org/10.1021/jf058059i

[12] Wang, H.F., Takeo, T., Ina, K. and Li, M.J. (1993) Characteristic Aroma Components of Keemun Black Tea. Journal of the Tea Science, 13, 61-68. (in Chinese)

[13] Rawat, R., Gulati, A., Babu, G.D.K., Acharya, R., Kaul, V.K. and Singh, B. (2007) Characterization of Volatile Components of Kangra Orthodox Black Tea by Gas Chromatography-Mass Spectrometry. Food Chemistry, 105, 229-235. http://dx.doi.org/10.1016/j.foodchem.2007.03.071

[14] Tontul, I., Torun, M., Dincer, C., Sahin-Nadeem, H., Topuz, A., Turna, T., et al. (2012) Comparative Study on Volatile Compounds in Turkish Green Tea Powder: Impact of Tea Clone, Shading Level and Shooting Period. Food Research International, 53, 744-750. http://dx.doi.org/10.1016/j.foodres.2012.12.026

[15] Romeo, V., Ziino, M., Giuffrida, D., Condurso, C. and Verzera, A. (2007) Flavour Profile of Capers (Capparis spinosa L.) from the Eolian Archipelago by HS-SPME/GC-MS. Food Chemistry, 101, 1272-1278. http://dx.doi.org/10.1016/j.foodchem.2005.12.029

[16] Wang, H.F. (1989) Tea flavor and Aroma. Chinese Tea.

[17] Gulati, A. and Ravindranath, S.D. (1996) Seasonal Variations in Quality of Kangra Tea (Camellia sinensis (L) O Kuntze) in Himachal Pradesh. Journal of the Science of Food and Agriculture, 71, 231-236. http://dx.doi.org/10.1002/(SICI)1097-0010(199606)71:2<231::AID-JSFA573>3.0.CO;2-Y 